\title{
Development requires activation but not phosphorylation of $\beta 1$ integrins
}

\author{
Yuliya Pylayeva ${ }^{1,2,4}$ and Filippo G. Giancotti ${ }^{1,3}$ \\ ${ }^{1}$ Cell Biology Program, Memorial Sloan-Kettering Cancer Center, New York, New York, USA; ${ }^{2}$ Sloan-Kettering Division, \\ Joan and Sanford I. Weill Graduate School of Medical Sciences, Cornell University, New York, New York, USA
}

Named after the ability of many of them to "integrate" the extracellular matrix with the intracellular cytoskeleton, integrins are well-characterized mediators of cellular adhesion and signaling (Giancotti and Ruoslahti 1999; Hynes 2002). Each integrin consists of an $\alpha$ and a $\beta$ subunit and binds to a distinct, but often overlapping, spectrum of ligands. Whereas $\beta 1$ integrins mediate cell adhesion to extracellular matrix components, $\beta 2$ integrins play key roles in immune cell recognition and activation by interacting with counterreceptors of the Ig superfamily, and $\alpha \mathrm{IIb} \beta 3$ orchestrates platelet aggregation by binding to the polyvalent blood protein fibrinogen. Genetic studies using mouse models have demonstrated that $\beta 1$ integrins have unique roles in embryonic development, hematopoiesis, wound healing, and cancer (Brakebusch et al. 1997; Grose et al. 2002; White et al. 2004). Successful execution of a number of physiological processes requires precisely choreographed changes in the activity of several integrins. The regulation of integrin functions is complex, and recent studies suggest that it hinges on long-range structural changes, which are propagated across the plasma membrane in both directions (Hynes 2002). In spite of its importance, genetic analysis of this aspect of integrin function has lagged behind. A new paper by Chen et al. (2006), published in the April 15 issue of Genes and Development, intends to remedy this imbalance.

Many integrins are maintained in a default low-affinity state and, hence, need to be activated to exert their function. The past decade has seen the emergence and consolidation of two major paradigms for integrin activation and signaling. The first describes the process through which cytoplasmic signals trigger integrin activation ("inside-to-outside" integrin signaling) (Ginsberg et al. 1992). Most, perhaps all, activating signals promote the binding of talin to the cytoplasmic portion of the integrin $\beta$ subunit (Liddington and Ginsberg 2002). Talin binding promotes a separation of the integrin cytoplas-

Correspondence.

${ }^{3}$ E-MAIL f-giancotti@ski.mskcc.org; FAX (212) 794-6236.

${ }^{4}$ E-MAIL yvp2001@med.cornell.edu; FAX (212) 794-6236.

Article and publication are at http://www.genesdev.org/cgi/doi/10.1101/ gad.1432006. mic tails and triggers a series of long-range conformation changes, including a "switch-blade" movement of the integrin head domains, resulting in increased availability of the extracellular ligand-binding site (Shimaoka et al. 2002). The immediate outcome of this form of regulation is an increase in the affinity of integrins for their matrix ligands. The second process, "outside-to-inside" integrin signaling, flows in the opposite direction. Upon binding to extracellular matrix components, integrins multimerize and recruit complexes of cytoskeletal and signaling molecules. Using this latter mechanism, integrins cooperate with receptors for cytokines and growth factors to control a multitude of cellular functions, including cell adhesion, migration, survival, differentiation, and proliferation (Assoian and Schwartz 2001; Miranti and Brugge 2002; Giancotti and Tarone 2003). Both inside-to-outside and outside-to-inside integrin signaling rely on a combination of regulatory controls that involves alterations in the structure of the receptors' cytoplasmic domains, long-range conformational changes in integrin structure, a steep increase in ligand-binding affinity, and finally, clustering of integrins and downstream signal transduction.

Mutagenesis and structural studies have painted a particularly vivid picture of integrin activation. Integrins are maintained inactive by interactions between the transmembrane domains and the membrane-proximal segments of the cytoplasmic tails of their constituent subunits (Fig. 1; Liddington and Ginsberg 2002). Substitution with Ala of an Asp residue in the membraneproximal segment of the $\beta$ subunit or an Arg residue in the corresponding region of the $\alpha$ subunit causes constitutive integrin activation, suggesting that a salt bridge between the side chains of the two amino acids stabilizes the inactive conformation (Hughes et al. 1996). In agreement with this notion, forced dimerization of the $\alpha$ and $\beta$ tails prevents integrin activation (Lu et al. 2001).

What is the mechanism through which cytoplasmic signals disrupt the $\alpha-\beta$ tail "clasp"? The C-terminal portion of all $\beta$ subunits contains two tandem NPxY motifs, and compelling evidence indicates that the $\mathrm{N}$-terminal motif functions to "unclasp" the integrin tails (Fig. 1). NMR structural analysis indicates that this motif forms a $\beta$ turn, creating a binding interface for a phospho-tyro- 


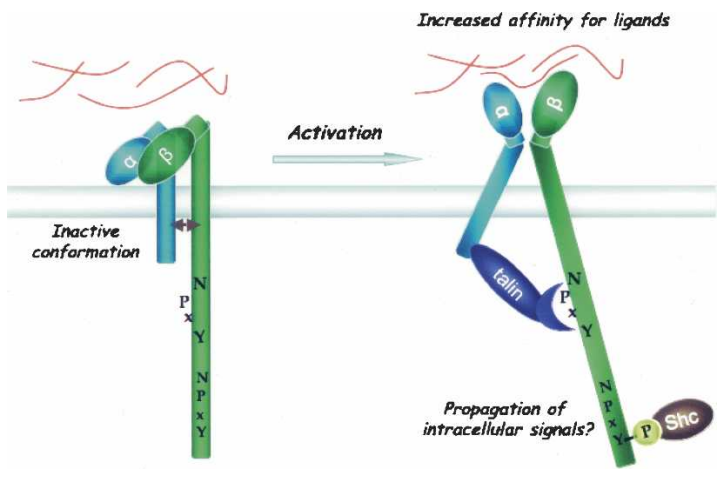

Figure 1. Model of integrin activation and signaling. Two predominant allosteric integrin conformations have been documented: the inactive (low-affinity) state and active (high-affinity) state. The inactive state is maintained by interactions between the transmembrane domains and the membraneproximal segments of the cytoplasmic tails of their constituent subunits (C-terminal clasp). Integrins can be activated by ligand binding or by straightening and separation of the cytoplasmic tails via interactions with cytoplasmic activators (e.g., talin).

sine-binding (PTB) domain (Forman-Kay and Pawson 1999; Ulmer et al. 2001). In fact, Calderwood et al. (1999) showed that binding of the PTB-containing FERM domain of talin to the $\mathrm{N}$-terminal NPxY motif of $\beta 3$ and other $\beta$ subunits induces integrin activation. The importance of this interaction is demonstrated by the observation that small interfering RNA (siRNA)-mediated silencing of talin prevents integrin activation (Tadokoro et al. 2003). In addition, mutation of the N-terminal NPxY motif inhibits integrin interaction with the actin cytoskeleton at focal contacts (Reszka et al. 1992). NMR studies demonstrate that the talin head domain disrupts the association of $\alpha-\beta$ tail peptides, suggesting that talin binding to the N-terminal NPxY motif is sufficient to "unclasp" the integrin $\alpha$ and $\beta$ subunit cytotails (Vinogradova et al. 2002). These results indicate that talin is key to both integrin activation and integrin association with the cytoskeleton.

The function of the C-terminal NPxY motif is less understood. However, binding of the PTB-domain protein ICAP- $1 \alpha$ to this motif interferes with cell spreading and assembly of focal contacts, presumably by suppressing binding of talin to the upstream motif (Bouvard et al. 2003). Moreover, the C-terminal motif of $\beta 3$ has been implicated in the recruitment of the signaling adaptor Shc in platelets (Fig. 1; Cowan et al. 2000; Phillips et al. 2001). In contrast to the $\beta 1$ integrin, which is not detectably phosphorylated in normal cells (Johansson et al. 1994), the $\beta 3$ subunit undergoes tyrosine phosphorylation during platelet aggregation (Blystone et al. 1997; Jenkins et al. 1998). The importance of tyrosine phosphorylation of $\beta 3$ has been examined in vivo using a knock-in mouse model, where each of the tyrosines in the NPxY motifs of $\beta 3$ integrin was replaced by a Phe ( $\beta 3$ diYF mice) (Law et al. 1999). The mutations did not seem to affect inside-out signaling in cells, since initial ADP-induced aggregation rates and fibrinogen binding of stimu- lated platelets were not perturbed. Outside-to-inside signaling, however, was impaired, as platelets exhibited defects in maintaining their aggregation following ADP stimulation. Consequently, the mice displayed an increased propensity to rebleed after clotting.

The tyrosine residues in the NPxY motifs of integrin $\beta$ subunits are putative sites for tyrosine kinase-mediated phosphorylation. In fact, early studies showed that $\beta 1$ integrins become phosphorylated on tyrosine in cells transformed with oncogenic tyrosine kinases (Hirst et al. 1986). Notably, this phosphorylation correlated with decreased integrin binding to both fibronectin and talin in vitro, suggesting a molecular mechanism for disruption of adhesion in neoplastically transformed cells (Tapley et al. 1989). Accordingly, Phe substitutions at both NPxY motifs in $\beta 1$ integrins reduced assembly of focal contacts and matrix deposition of fibronectin in cells transformed by the v-Src oncogene (Sakai et al. 2001).

The FERM domain of talin binds to integrins via a novel variant of the canonical PTB domain-NPxY ligand interaction (Garcia-Alvarez et al. 2003). Phosphorylation of the NPxY motif is predicted to disrupt this interaction, as well as that of ICAP- $1 \alpha$, with integrins. By contrast, binding of the signaling adaptor Shc to $\beta 3$ appears to require phosphorylation of the C-terminal NPxY motif (Fig. 1; Cowan et al. 2000). Other physiologically relevant PTB domain interactions may be similarly regulated, as integrin $\beta$ tails can bind in vitro to several PTB domain proteins, including Numb, Dok-1, EPS8, tensin, and Dab (Calderwood et al. 2003). Based on these observations, it has been proposed that tyrosine phosphorylation of the NPxY motifs can function as a "molecular switch," contributing to diversity of signaling following integrin-dependent adhesion (Liddington and Ginsberg 2002; Calderwood et al. 2003).

Chen et al. (2006) have chosen to address this question by studying the role of the NPxY motifs in $\beta 1$ integrins. The $\beta 1$ subunit is expressed in most cells from the earliest stages of development until adulthood, and it combines with 12 distinct $\alpha$ subunits to form receptors that bind to fibronectin, laminins, collagens, and a variety of other matrix components. Not surprisingly, ablation of $\beta 1$ causes early, preimplantation embryonic lethality: The inner cell mass does not develop properly, the blastocoele collapses, and profound defects in endoderm morphogenesis and migration ensue (Fassler and Meyer 1995; Stephens et al. 1995).

To examine whether the Tyr residues in NPxY motifs are necessary for proper functioning of $\beta 1$ integrins, Chen et al. (2006) first introduced Ala substitutions at both residues in ES cells. Targeting both NPxY motifs avoided the possibility of compensatory binding of cytoplasmic-interacting partners to the nonmutated tyrosine (Fig. 2). Homozygous embryos ( $\beta 1$ diYA embryos) failed before implantation, essentially like $\beta 1$-null embryos, demonstrating that the Tyr residues in NPxY motifs are absolutely required for $\beta 1$ integrin function during early development.

They next addressed the significance of phosphorylation of these residues by generating another set of knock- 


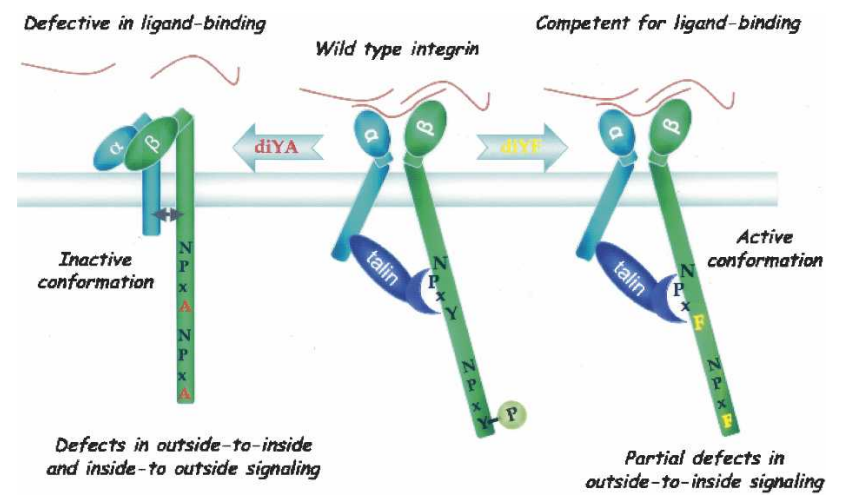

Figure 2. Proposed effects of the diYA and the diYF mutation on $\beta 1$ integrins. To investigate the role of NPxY motifs in $\beta 1$ activation and signaling, Chen et al. (2006) have generated two knock-in mouse models. The diYA mutants are embryonic lethal and fully phenocopy $\beta 1$-null embryos. Further experiments demonstrate that conversion of tyrosines to alanines renders $\beta 1$ integrins inactive. By contrast, diYF mutant mice survive to adulthood, suggesting that tyrosine phosphorylation of the NPxY motifs of $\beta 1$ is dispensable for normal mouse development. DiYF $\beta 1$ integrins are fully competent for inside-tooutside signaling and ligand binding. A moderate decrease in stabilization of platelet adhesion to collagen under flow indicates that the outside-to-inside arm of $\beta 1$ signaling is modestly compromised in these cells.

in mutants, this time featuring conservative substitutions of both Tyr residues with Phe residues ( $\beta 1$ diYF mice) (Fig. 2). This approach preserved the hydrophobicity conferred by tyrosines but eliminated the contribution of phosphorylation. Surprisingly, homozygous $\beta 1$ diYF mice were born alive and grew into adulthood healthy, indicating that phosphorylation of the $\beta 1$ cytoplasmic tail is not essential for development and normal adult life.

The importance of $\beta 1$ integrin cytoplasmic tyrosines after embryogenesis was assessed using elegant chimera studies, where $\beta 1$ diYA and diYF ES cells were injected into wild-type blastocysts. Whereas diYF cells were able to contribute to all tissues that were analyzed, diYA cells did not participate in the development of most organs, behaving essentially like $\beta 1$-null cells in similar chimeras. These observations provide strong evidence that the tyrosine residues in NPxY motifs are necessary for $\beta 1$ function during development. Phosphorylation of these tyrosines, however, seems to be dispensable.

What is the mechanism by which the diYA mutation disrupts integrin $\beta 1$ function? Chen et al. (2006) provide evidence that cells bearing this mutation exhibit profound defects in binding to fibronectin and laminin. In addition, their $\beta 1$ integrins were not recognized by the activation-specific monoclonal antibody 9EG7. Therefore, the diYA mutation disables the inside-to-outside arm of integrin signaling. Because loss of talin phenocopies the effect of ablation of $\beta 1$ integrins in worms and flies (Brown et al. 2002; Cram et al. 2003), the profound effect of the diYA mutation is probably due to loss of binding of talin. Not surprisingly, $\beta 1$ diYA platelets did not adhere well to collagen under flow. Defective outside-to-inside signaling may contribute to a small extent to the phenotype, as $\beta 1$ diYF platelets showed marginally defective adhesion to collagen in the same assay. Albeit of much smaller intensity, this latter defect is reminiscent of the post-clotting defect observed in $\beta 3$ diYF platelets, suggesting that tyrosine phosphorylation contributes to adhesion strengthening in platelets.

The conclusions drawn from the analysis of $\beta 1$ diYF mutant mice underscore the necessity for a rigorous genetic analysis of integrin function. Whereas tyrosine phosphorylation may contribute to regulation of $\alpha \operatorname{IIb} \beta 3$ and, to a smaller extent, $\alpha 2 \beta 1$ in platelets, this modification does not appear to affect the function of most $\beta 1$ integrins during development. It remains to be resolved whether this dichotomy arises from differences in integrin signaling between platelets and other cells or differences between $\beta 1$ and $\beta 3$ integrins. Notably, Phe substitution at both NPxY motifs does not impair integrin $\beta 1$ mediated recruitment of Shc and activation of Ras-ERK signaling in mouse fibroblasts (Wary et al. 1996), in agreement with the observation that these motifs in $\beta 1$ are not detectably phosphorylated in cultured cells (Johansson et al. 1994). Rather, $\beta 1$ integrins recruit Shc through their $\alpha$ subunit (Wary et al. 1998) or through Focal Adhesion Kinase (Schlaepfer et al. 1998). A second question relates to the relative contribution of the Cterminal NPxY motif. Whereas the major function of the $\mathrm{N}$-terminal motif is to recruit talin, the C-terminal motif can recruit ICAP- $1 \alpha$ and possibly other PTB domain proteins. More specific loss-of-function mutations will be required to better define its function. Finally, we should not avoid considering the possibility that phosphorylation of the NPxY motifs becomes important under conditions of cellular distress, such as transformation or inflammation. The data linking tyrosine phosphorylation of $\beta 1$ to disruption of adhesion and modified signaling in cells transformed by oncogenic tyrosine kinases are compelling. We speculate that oncogenic tyrosine kinases may hijack the integrin NPxY motifs to disrupt adhesion and promote constitutive signaling. Breeding the $\beta 1$ diYF mice into relevant mouse models of cancer will reveal if this is indeed the case.

\section{References}

Assoian, R.K. and Schwartz, M.A. 2001. Coordinate signaling by integrins and receptor tyrosine kinases in the regulation of G1 phase cell-cycle progression. Curr. Opin. Genet. Dev. 11: 48-53.

Blystone, S.D., Williams, M.P., Slater, S.E., and Brown, E.J. 1997. Requirement of integrin $\beta 3$ tyrosine 747 for $\beta 3$ tyrosine phosphorylation and regulation of $\alpha \mathrm{v} \beta 3$ avidity. J. Biol. Chem. 272: 28757-28761.

Bouvard, D., Vignoud, L., Dupe-Manet, S., Abed, N., Fournier, H.N., Vincent-Monegat, C., Retta, S.F., Fassler, R., and Block, M.R. 2003. Disruption of focal adhesions by integrin cytoplasmic domain-associated protein-1 $\alpha$. J. Biol. Chem. 278: 6567-6574.

Brakebusch, C., Hirsch, E., Potocnik, A., and Fassler, R. 1997. Genetic analysis of $\beta 1$ integrin function: Confirmed, new 
and revised roles for a crucial family of cell adhesion molecules. J. Cell Sci. 110: 2895-2904.

Brown, N.H., Gregory, S.L., Rickoll, W.L., Fessler, L.I., Prout, M., White, R.A., and Fristrom, J.W. 2002. Talin is essential for integrin function in Drosophila. Dev. Cell 3: 569-579.

Calderwood, D.A., Zent, R., Grant, R., Rees, D.J., Hynes, R.O., and Ginsberg, M.H. 1999. The Talin head domain binds to integrin $\beta$ subunit cytoplasmic tails and regulates integrin activation. J. Biol. Chem. 274: 28071-28074.

Calderwood, D.A., Fujioka, Y., de Pereda, J.M., Garcia-Alvarez, B., Nakamoto, T., Margolis, B., McGlade, C.J., Liddington, R.C., and Ginsberg, M.H. 2003. Integrin $\beta$ cytoplasmic domain interactions with phosphotyrosine-binding domains: A structural prototype for diversity in integrin signaling. Proc. Nat1. Acad. Sci. 100: 2272-2277.

Chen, H., Zou, Z., Sarratt, K.L., Zhou, D., Zhang, M., Sebzda, E., Hammer, D.A., and Kahn, M.L. 2006. In vivo $\beta 1$ integrin function requires phosphorylation-independent regulation by cytoplasmic tyrosines. Genes \& Dev. 20: 927-932.

Cowan, K.J., Law, D.A., and Phillips, D.R. 2000. Identification of shc as the primary protein binding to the tyrosine-phosphorylated $\beta 3$ subunit of $\alpha \operatorname{IIb} \beta 3$ during outside-in integrin platelet signaling. J. Biol. Chem. 275: 36423-36429.

Cram, E.J., Clark, S.G., and Schwarzbauer, J.E. 2003. Talin lossof-function uncovers roles in cell contractility and migration in C. elegans. J. Cell Sci. 116: 3871-3878.

Fassler, R. and Meyer, M. 1995. Consequences of lack of $\beta 1$ integrin gene expression in mice. Genes \& Dev. 9: 1896 1908.

Forman-Kay, J.D. and Pawson, T. 1999. Diversity in protein recognition by PTB domains. Curr. Opin. Struct. Biol. 9: 690-695.

Garcia-Alvarez, B., de Pereda, J.M., Calderwood, D.A., Ulmer, T.S., Critchley, D., Campbell, I.D., Ginsberg, M.H., and Liddington, R.C. 2003. Structural determinants of integrin recognition by talin. Mol. Cell 11: 49-58.

Giancotti, F.G. and Ruoslahti, E. 1999. Integrin signaling. Science 285: 1028-1032.

Giancotti, F.G. and Tarone, G. 2003. Positional control of cell fate through joint integrin/receptor protein kinase signaling. Annu. Rev. Cell Dev. Biol. 19: 173-206.

Ginsberg, M.H., Du, X., and Plow, E.F. 1992. Inside-out integrin signalling. Curr. Opin. Cell Biol. 4: 766-771.

Grose, R., Hutter, C., Bloch, W., Thorey, I., Watt, F.M., Fassler, R., Brakebusch, C., and Werner, S. 2002. A crucial role of $\beta 1$ integrins for keratinocyte migration in vitro and during cutaneous wound repair. Development 129: 2303-2315.

Hirst, R., Horwitz, A., Buck, C., and Rohrschneider, L. 1986. Phosphorylation of the fibronectin receptor complex in cells transformed by oncogenes that encode tyrosine kinases. Proc. Nat1. Acad. Sci. 83: 6470-6474.

Hughes, P.E., Diaz-Gonzalez, F., Leong, L., Wu, C., McDonald, J.A., Shattil, S.J., and Ginsberg, M.H. 1996. Breaking the integrin hinge: A defined structural constraint regulates integrin signaling. J. Biol. Chem. 271: 6571-6574.

Hynes, R.O. 2002. Integrins: Bidirectional, allosteric signaling machines. Cell 110: 673-687.

Jenkins, A.L., Nannizzi-Alaimo, L., Silver, D., Sellers, J.R., Ginsberg, M.H., Law, D.A., and Phillips, D.R. 1998. Tyrosine phosphorylation of the $\beta 3$ cytoplasmic domain mediates integrin-cytoskeletal interactions. J. Biol. Chem. 273: 13878 13885.

Johansson, M.W., Larsson, E., Luning, B., Pasquale, E.B., and Ruoslahti, E. 1994. Altered localization and cytoplasmic domain-binding properties of tyrosine-phosphorylated $\beta 1$ integrin. J. Cell Biol. 126: 1299-1309.
Law, D.A., DeGuzman, F.R., Heiser, P., Ministri-Madrid, K., Killeen, N., and Phillips, D.R. 1999. Integrin cytoplasmic tyrosine motif is required for outside-in $\alpha \operatorname{IIb} \beta 3$ signalling and platelet function. Nature 401: 808-811.

Liddington, R.C. and Ginsberg, M.H. 2002. Integrin activation takes shape. J. Cell Biol. 158: 833-839.

Lu, C., Takagi, J., and Springer, T.A. 2001. Association of the membrane proximal regions of the $\alpha$ and $\beta$ subunit cytoplasmic domains constrains an integrin in the inactive state. $J$. Biol. Chem. 276: 14642-14648.

Miranti, C.K. and Brugge, J.S. 2002. Sensing the environment: A historical perspective on integrin signal transduction. Nat. Cell Biol. 4: E83-E90.

Phillips, D.R., Prasad, K.S., Manganello, J., Bao, M., and Nannizzi-Alaimo, L. 2001. Integrin tyrosine phosphorylation in platelet signaling. Curr. Opin. Cell Biol. 13: 546-554.

Reszka, A.A., Hayashi, Y., and Horwitz, A.F. 1992. Identification of amino acid sequences in the integrin $\beta 1$ cytoplasmic domain implicated in cytoskeletal association. J. Cell Biol. 117: 1321-1330.

Sakai, T., Jove, R., Fassler, R., and Mosher, D.F. 2001. Role of the cytoplasmic tyrosines of $\beta 1 \mathrm{~A}$ integrins in transformation by v-src. Proc. Nat1. Acad. Sci. 98: 3808-3813.

Schlaepfer, D.D., Jones, K.C., and Hunter, T. 1998. Multiple Grb2-mediated integrin-stimulated signaling pathways to ERK2/mitogen-activated protein kinase: Summation of both c-Src- and focal adhesion kinase-initiated tyrosine phosphorylation events. Mol. Cell. Biol. 18: 2571-2585.

Shimaoka, M., Takagi, J., and Springer, T.A. 2002. Conformational regulation of integrin structure and function. Annu. Rev. Biophys. Biomol. Struct. 31: 485-516.

Stephens, L.E., Sutherland, A.E., Klimanskaya, I.V., Andrieux, A., Meneses, J., Pedersen, R.A., and Damsky, C.H. 1995. Deletion of $\beta 1$ integrins in mice results in inner cell mass failure and peri-implantation lethality. Genes \& Dev. 9: 18831895.

Tadokoro, S., Shattil, S.J., Eto, K., Tai, V., Liddington, R.C., de Pereda, J.M., Ginsberg, M.H., and Calderwood, D.A. 2003. Talin binding to integrin $\beta$ tails: A final common step in integrin activation. Science 302: 103-106.

Tapley, P., Horwitz, A., Buck, C., Duggan, K., and Rohrschneider, L. 1989. Integrins isolated from Rous sarcoma virus-transformed chicken embryo fibroblasts. Oncogene 4: 325-333.

Ulmer, T.S., Yaspan, B., Ginsberg, M.H., and Campbell, I.D. 2001. NMR analysis of structure and dynamics of the cytosolic tails of integrin $\alpha \mathrm{IIb} \beta 3$ in aqueous solution. Biochemistry 40: 7498-7508.

Vinogradova, O., Velyvis, A., Velyviene, A., Hu, B., Haas, T., Plow, E., and Qin, J. 2002. A structural mechanism of integrin $\alpha(\mathrm{IIb}) \beta(3)$ 'inside-out' activation as regulated by its cytoplasmic face. Cell 110: 587-597.

Wary, K.K., Mainiero, F., Isakoff, S.J., Marcantonio, E.E., and Giancotti, F.G. 1996. The adaptor protein Shc couples a class of integrins to the control of cell cycle progression. Cell 87: 733-743.

Wary, K.K., Mariotti, A., Zurzolo, C., and Giancotti, F.G. 1998. A requirement for caveolin-1 and associated kinase Fyn in integrin signaling and anchorage-dependent cell growth. Cell 94: 625-634.

White, D.E., Kurpios, N.A., Zuo, D., Hassell, J.A., Blaess, S., Mueller, U., and Muller, W.J. 2004. Targeted disruption of $\beta 1$-integrin in a transgenic mouse model of human breast cancer reveals an essential role in mammary tumor induction. Cancer Cell 6: 159-170. 


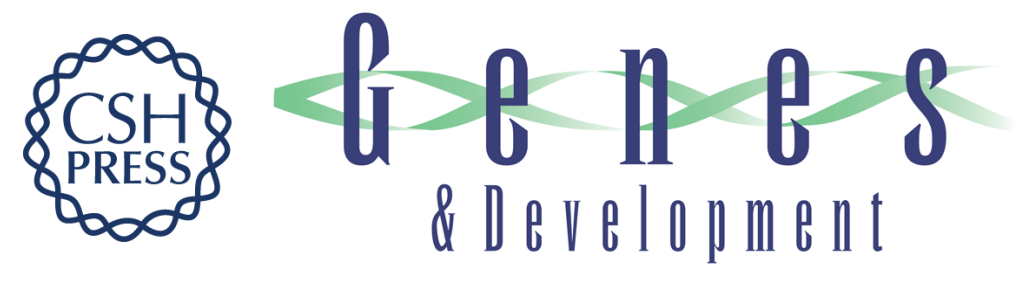

\title{
Development requires activation but not phosphorylation of $\beta 1$ integrins
}

\author{
Yuliya Pylayeva and Filippo G. Giancotti
}

Genes Dev. 2006, 20:

Access the most recent version at doi:10.1101/gad.1432006

\section{Related Content In vivo ${ }^{21}$ integrin function requires phosphorylation-independent regulation by cytoplasmic tyrosines \\ Hong Chen, Zhiying Zou, Kendra L. Sarratt, et al. \\ Genes Dev. UNKNOWN , 2006 20: 927-932 \\ References This article cites 39 articles, 22 of which can be accessed free at: \\ http://genesdev.cshlp.org/content/20/9/1057.full.html\#ref-list-1 \\ Articles cited in: \\ http://genesdev.cshlp.org/content/20/9/1057.full.html\#related-urls \\ License \\ Email Alerting \\ Receive free email alerts when new articles cite this article - sign up in the box at the top Service

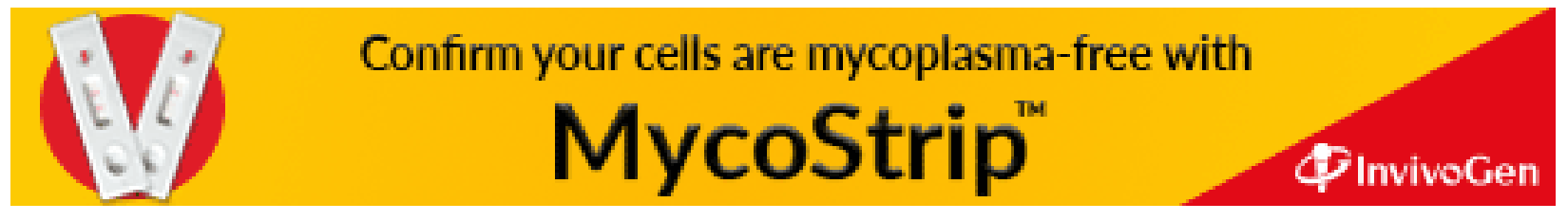

